\title{
Assimilating scatterometer soil moisture data into conceptual hydrologic models at the regional scale
}

\author{
J. Parajka ${ }^{1, *}$, V. Naeimi ${ }^{2}$, G. Blöschl ${ }^{1}$, W. Wagner ${ }^{2}$, R. Merz ${ }^{1}$, and K. Scipal ${ }^{2}$ \\ ${ }^{1}$ Institute for Hydraulic and Water Resources Engineering, Vienna University of Technology, Austria \\ ${ }^{2}$ Institute of Photogrammetry and Remote Sensing, Vienna University of Technology, Austria \\ * on leave from: Institute of Hydrology, Slovak Academy of Sciences, Bratislava, Slovakia
}

Received: 15 November 2005 - Published in Hydrol. Earth Syst. Sci. Discuss.: 22 December 2005

Revised: 22 February 2006 - Accepted: 22 March 2006 - Published: 17 May 2006

\begin{abstract}
This paper examines the potential of scatterometer data from ERS satellites for improving hydrological simulations in both gauged and ungauged catchments. We compare the soil moisture dynamics simulated by a semidistributed hydrologic model in 320 Austrian catchments with the soil moisture dynamics inferred from the satellite data. The most apparent differences occur in the Alpine areas. Assimilating the scatterometer data into the hydrologic model during the calibration phase improves the relationship between the two soil moisture estimates without any significant decrease in runoff model efficiency. For the case of ungauged catchments, assimilating scatterometer data does not improve the daily runoff simulations but does provide more consistent soil moisture estimates. If the main interest is in obtaining estimates of catchment soil moisture, reconciling the two sources of soil moisture information seems to be of value because of the different error structures.
\end{abstract}

\section{Introduction}

Soil moisture has an important influence on hydrological and meteorological processes, although the volume of water stored as soil moisture represents only a small proportion of liquid freshwater on the Earth. Soil moisture controls the partitioning of radiation into latent and sensible heat and hence the water balance of catchments in most climates. Soil moisture also controls the magnitude of floods through partitioning rainfall into runoff and infiltration. A realistic representation of soil moisture is therefore essential for numerous purposes.

In the past years there has been a concerted effort to better understand the spatio-temporal dynamics of soil moisture in small catchments (e.g. Western et al., 1998; Western and

Correspondence to: J. Parajka

(parajka@hydro.tuwien.ac.at)
Blöschl, 1999; Bárdossy and Lehmann, 1998). These studies have provided a lot of insight into how soil moisture varies in space as a function of terrain, soil characteristics and what the spatial statistical characteristics are. The ground based measurements used in the above studies were based on gravimetric sampling, on Neutron moisture meters or on Time Domain Reflectometry. All methods are sufficiently accurate to allow a meaningful interpretation of the measurements and they can be calibrated relatively easily. The main drawback of ground based measurements, however, is that they can only cover relatively small areas due to logistic constraints, and the spatial support or foot print of a measurement is usually on the order of a few centimetres. This makes it very difficult to estimate meaningful spatial averages over medium sized to large catchments. There have been a number of attempts to relate ground measurements to larger catchment scales (e.g. Western et al., 2002) but there are two alternative methods of estimating the soil moisture dynamics that are more relevant for large regions. The first method consists of estimating soil moisture based on hydrological models. The second method consists of back-calculating soil moisture from satellite observations. Each of these alternative methods has its advantages and disadvantages. The main advantage of using hydrological models for estimating soil moisture is that they explicitly represent areal averages over catchments and the input data are usually available over large areas. Also, soil moisture simulated by these models is considered representative over the entire root zone, which is the hydrologically most important zone in terms of runoff generation. The main disadvantage of this type of model is that there is always some degree of calibration needed to accurately represent the hydrological processes in a particular case (Blöschl and Grayson, 2002). An alternative approach of estimating soil moisture is the use of satellite data. A range of platforms exists or will be shortly in place (e.g. Schultz and Engman, 2000; Jackson, 2005). Out of these, radar microwave sensors are particularly appealing for retrieving soil

Published by Copernicus GmbH on behalf of the European Geosciences Union. 
moisture. Radar measurements of bare soil surfaces are very sensitive to the water content in the soil surface layer due to the pronounced increase in the soil dielectric constant with increasing water content (Ulaby et al., 1982). In a hydrologic context, the main advantage of using spaceborne sensors for soil moisture retrieval is that they provide an integral value over an area rather than point values. Also, many of these data sources are available at a global scale, so they are ideally suited for the ungauged catchment problem. However, there are also a number of disadvantages in a hydrologic context. The main limitation is probably the limited penetration depth. Microwaves only sense the top few centimetres of the soil or less while, for hydrologic predictions, the soil moisture in deeper soil layers is just as important. Hydrological use of this type of data hence needs to carefully consider the implications of the limited penetration depth.

It appears an obvious thing to merge these two branches of soil moisture estimation, hydrological models and spaceborne data, to benefit from the advantages of both methods. There has indeed been a substantial body of work in recent years geared towards combining hydrologic or atmospheric models and spaceborne data. These methods of integrating satellite data in a consistent manner with model predictions are usually referred to as Data Assimilation (DA) procedures. DA methods are quantitative, objective methods to infer the state of a hydrologic system from irregularly distributed and temporally inconsistent data sets with differing accuracies, providing at the same time more reliable information about the predictive uncertainty in model forecasts (McLaughlin, 1995). Existing DA schemes were developed mainly for numerical weather prediction, where the most commonly used techniques are optimal interpolation and variational minimisation (Daley, 1991). Spurred by the success of DA in other fields and by a few early hydrological investigations (e.g., Entekhabi et al., 1994; Milly, 1986) DA has attracted a lot of attention in hydrology in recent years (Wigneron et al., 1999; Hoeben and Troch, 2000; Houser et al., 2000; Boni et al., 2001; Walker et al., 2001; Francois et al., 2003, Schuurmans et al., 2003). These papers have mostly focused on the assimilation of surface soil moisture data into land surface models. Some of these studies have simulated the real time mode and have hence used a scheme for updating the state variables of the model. Houser et al. (2000) and Walker et al. (2001) assessed the relative merits of updating schemes including direct insertion, statistical corrections, Newtonian nudging, optimal interpolation, Kalman filtering and ensemble Kalman filtering. Another important application is the simulation mode where the soil moisture data are used in the calibration of land surface models together with other data sources.

The rationale of combining two sources of information on soil moisture, hydrological models and satellite data, is that even though both sources have clear limitations and are associated with significant uncertainty it is their combination that should help reduce the uncertainty of the integrated esti- mates. The main hypothesis of this is that the error structures of the estimates from these two methods are likely different, so one would expect a combination of the two sources to be less biased and exhibit less random error than any of the two sources individually. The hypothesis of different error structures is plausible because of a number of reasons. Most importantly, the estimates come from completely different instruments, ground based instruments and spaceborne sensors, so one would also expect their errors to be different. Also, the models that estimate soil moisture in these two sources have a different structure and they are calibrated in different ways.

The aim of this paper is to compare the soil moisture dynamics estimated from hydrological models with those inferred from satellite data, and to examine the potential of scatterometer data from ERS satellites for improving hydrological simulations in both gauged and ungauged catchments.

This paper is organised as follows. The data section provides an overview of satellite (scatterometer) data as well as the climate and hydrologic data. The methods section presents the model, the method of reconciling the penetration depth of the satellite data with the model estimation, the calibration procedure, and evaluates the model performance. In the next sections we compare soil moisture derived from the scatterometer data with the soil moisture simulations obtained by the hydrologic model. We then present the results of assimilating the scatterometer data into the hydrologic model during the calibration phase. Finally, we analyse the potential of the scatterometer soil moisture estimates for predictions in ungauged catchments. The paper concludes with remarks on possibilities for improving satellite derived soil moisture estimates.

\section{Data}

This study is set in Austria and the data are from the period 1991-2000. The dataset includes soil moisture estimates from the ERS scatterometer, climatic data used for simulating soil moisture using a hydrologic model as well as runoff data.

\subsection{Scatterometer data}

The satellite soil moisture data used in this study are taken from the Global Soil Moisture Archive 1992-2000 located at http://www.ipf.tuwien.ac.at/radar/ers-scat/home.htm (Scipal et al., 2002). The archive is based on ERS Scatterometer data and comprises global surface soil moisture data and indicators of root zone soil moisture sampled at ten-day intervals.

Scatterometers are active microwave sensors characterised by a coarse spatial but a high temporal resolution. To retrieve soil moisture information, scatterometers onboard of the European Remote Sensing Satellites ERS-1 and ERS-2, 


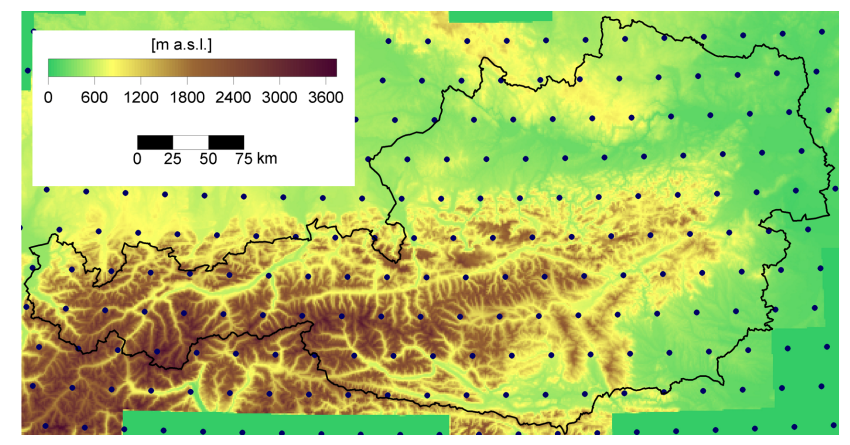

Fig. 1. Location of centroids of the pixels for the scatterometer data in Austria.

operated by the European Space Agency were used. The ERS scatterometer operates at $5.3 \mathrm{GHz}$ (C-band) vertical polarization, collecting backscatter measurements over an incidence angle range from $18^{\circ}$ to $57^{\circ}$ using three sideways looking antennae. The sensor achieves global coverage within 3 to 4 days where each beam provides measurements of radar backscatter from the sea and land surface for overlapping $50 \mathrm{~km}$ resolution cells with a $25 \mathrm{~km}$ grid spacing at approximately 10:30 am and 10:30 pm for ascending and descending tracks, respectively. Unfortunately, over Europe ERS scatterometer operations were often in conflict with Synthetic Aperture Radar (SAR) acquisitions which is why only 17$40 \%$ of all possible acquisitions were actually taken. The locations of the centroids of the pixels for Austria are presented in Fig. 1.

Scatterometry offers capabilities to infer soil moisture due to the strong variation of the dielectric constant of the soil with volumetric water content. However, scattering from land surfaces depends on other factors as well. Potential retrieval techniques must account for the confounding effects of surface roughness, vegetation, topography and soil texture. Retrieval of soil moisture for "The Global Soil Moisture Archive" is based on the change detection method developed by Wagner et al. (1999b). The method accounts for the effects of surface roughness, vegetation and heterogeneous land cover (Wagner et al., 1999a, b, c). It allows the retrieval of surface soil moisture information of the topmost $2 \mathrm{~cm}$ by comparing the instantaneous vegetation corrected backscatter coefficient to the lowest and highest backscatter coefficients observed in a nine year period (1992-2000). Under the assumption that within this period the respective area has been observed under completely dry (lowest backscatter coefficient) and saturated conditions (highest backscatter coefficient) the derived soil moisture information, $m_{s}$, is equivalent to the degree of saturation in relative units (ranging between 0 and $100 \%$ ).

\subsection{Climatic and hydrologic data}

The climatic data used to drive the hydrologic model include measurements of daily precipitation and snow depths at 1091 stations and daily air temperature at 212 climatic stations. To calibrate and verify the hydrologic model, daily runoff data from 320 gauged catchments were used with areas ranging from $10 \mathrm{~km}^{2}$ to $9770 \mathrm{~km}^{2}$ and a median of $196 \mathrm{~km}^{2}$. A more detailed description of the spatial distribution of the climate stations and the boundaries of the gauged catchments is presented in Parajka et al. (2005a).

The inputs to the hydrological model were prepared in two steps. First, the daily values of precipitation, snow depth and air temperature were spatially interpolated by methods that use elevation as auxiliary information. External drift kriging was used for precipitation and snow depths, and the leastsquares trend prediction method was used for air temperatures (Pebesma, 2001). The spatial distribution of potential evapotranspiration was estimated by a modified BlaneyCriddle method (Schrödter, 1985; Parajka et al., 2003) using daily air temperature and potential sunshine duration calculated by the Solei-32 model (Mészároš et al., 2002, http: //www.ih.savba.sk/software/solei/) that incorporates shading by surrounding terrain. In a second step, a digital elevation model with a $1 \times 1 \mathrm{~km}$ grid resolution was used for deriving $200 \mathrm{~m}$ elevation zones in each catchment. Time-series of daily precipitation, air temperature, potential evaporation and snow depth were then extracted for each of the elevation zones to be used in the hydrological simulations.

\section{Method}

\subsection{Hydrological model}

The hydrologic model used in this research is a semidistributed conceptual rainfall-runoff model, following the structure of the HBV model (Bergström, 1976, and Lindström et al., 1997). The model runs on a daily time step and consists of a snow routine, a soil moisture accounting routine and a flow routing routine. The soil moisture routine estimates root zone soil moisture by balancing evaporation and runoff output with precipitation input. The outputs are a function of root zone soil moisture as estimated by the model. More detailed information about the model structure and its hydrologic applications in Austria is presented, e.g., in Parajka et al. (2004, 2005a, b).

\subsection{Matching penetration depths}

The main challenge in combining spaceborne soil moisture with soil moisture represented in hydrological models are the shallow penetration depths of the spaceborne data. Some assumptions hence need to be made on the vertical distribution of soil moisture in the soil profile. A number of studies have applied representations of the one-dimensional 
Table 1. Model parameters and a priori distributions. $u$ and $v$ are the parameters of the Beta distribution (Eq. 9), $p_{l}$ and $p_{u}$ are the lower and upper bounds of the parameter space and $p_{\max }$ is the parameter value at which the Beta distribution is at a maximum (Eq. 7).

\begin{tabular}{lllllll}
\hline Parameter name & Model part & $p_{l}$ & $p_{u}$ & $u$ & $v$ & $p_{\max }$ \\
\hline $\mathrm{SCF}[-]$ & Snow & 1.0 & 1.5 & 1.2 & 4.0 & 1.03 \\
$\mathrm{DDF}\left[\mathrm{mm} /{ }^{\circ} \mathrm{C}\right.$ day] & Snow & 0.0 & 5.0 & 2.0 & 4.0 & 1.25 \\
$\mathrm{LP} / \mathrm{FC}[-]$ & Soil & 0.0 & 1.0 & 4.0 & 1.2 & 0.94 \\
$\mathrm{FC}[\mathrm{mm}]$ & Soil & 0.0 & 600.0 & 1.1 & 1.5 & 100.2 \\
$\beta[-]$ & Soil & 0.0 & 20.0 & 1.1 & 1.5 & 3.4 \\
$\mathrm{~K}_{0}[$ days] & Runoff & 0.0 & 2.0 & 2.0 & 4.0 & 0.5 \\
$\mathrm{~K}_{1}$ [days] & Runoff & 2.0 & 30.0 & 2.0 & 4.0 & 9.0 \\
$\mathrm{~K}_{2}$ [days] & Runoff & 30.0 & 180.0 & 1.05 & 1.05 & 105.0 \\
$\mathrm{C}_{P}[\mathrm{~mm} /$ day] & Runoff & 0.0 & 8.0 & 2.0 & 4.0 & 2.0 \\
$\mathrm{C}_{R}$ [days $\left./ \mathrm{mm}\right]$ & Runoff & 0.0 & 50.0 & 1.05 & 1.05 & 25.0 \\
$\mathrm{LS}_{U Z}[\mathrm{~mm}]$ & Runoff & 1.0 & 100.0 & 3.0 & 3.0 & 50.5 \\
\hline
\end{tabular}

Richards equation. Bernard et al. (1981), Prevot et al. (1984), and Bruckler and Witono (1989) used fixed head boundary condition in the one-dimensional Richards equation, and Entekhabi et al. (1994) updated the 1D state variables in the Richards equation using a Kalman filter. The difficulty with the Richards equation approach is that the soil physical characteristics need to be known in much detail which is usually not possible at the field scale. Also, it is unclear what is the value of an excessive level of detail in the vertical direction if the model is lumped over areas of hundreds of square kilometres. Because of this, simplifications of the Richards equation have been proposed which are invariantly some type of multilayer model. Two layer models of various variants have been proposed by Jackson et al. (1981) and Ottlé and VidalMadjar (1994) which they combined with the direct insertion updating approach. A two layer model based on basin average soil moisture has been suggested by Georgakakos and Baumer (1996). A three layer approach has been proposed by Houser et al. (2000) who applied a number of assimilation schemes. The relative merits have not yet been fully assessed but it seems clear that, given the spatial scales and data limitations, more parsimonious approaches are more appealing than the more sophisticated ones.

This paper therefore adopts an alternative approach. Rather than resolving the vertical profile to estimate surface soil moisture from root zone soil moisture an attempt is made to estimate root zone soil moisture from the surface values. The approach is pragmatic. The main idea is that surface soil moisture tends to fluctuate much more rapidly than root zone soil moisture. This is because the soil dampens the high frequencies as soil moisture infiltrates into the soil. Rather than solving the flow equations we represent the dampening effect by a linear, exponential filter in the time domain. In other words, a Taylor hypothesis is made to trade space for time.
The filtered values are termed the Soil Water Index, SWI:

$S W I(t)=\frac{\sum_{i} m_{s}\left(t_{i}\right) e^{-\frac{t-t_{i}}{T}}}{\sum_{i} e^{-\frac{t-t_{i}}{T}}}$

where $m_{s}$ is the retrieved surface soil moisture value at time $t_{i}$, ranging between 0 and 1 . The main parameter in the approach is the time constant of the filter or pseudo diffusivity $T$. In general, the pseudo diffusivity depends on soil properties including soil depth and the moisture state (Wagner et al., 1999b; Ceballos et al., 2005). As soil properties are not known quantitatively on a regional scale, this parameter was set to an a priori value of $T=20$ days (Wagner et al., 1999c) in this paper. This value is consistent with hydrological reasoning. The field capacity of Austrian soils as obtained by calibrating hydrological models (Merz and Blöschl, 2004), typically, is on the order of $150 \mathrm{~mm}$. Assuming a porosity of 0.3 , a pseudo diffusivity of 20 days would then translate into a wetting front celerity of $25 \mathrm{~mm}$ per day. This is a typical value for Austrian soils.

The Soil Water Index, SWI, is a non-dimensional index between 0 (completely dry), and 1 (saturated). The index has been shown to be bounded well by the wilting level and the point midway the field-capacity and total water capacity (Wagner et al., 1999b). Throughout this paper, the SWI index is used as a satellite estimate of relative root zone soil moisture.

In the hydrological model, $S_{S M}$ is the soil moisture of a top soil layer controlling runoff generation and actual evaporation (Eq. (A.4) of Parajka et al., 2006). This soil moisture has been scaled by the field capacity, $F C$, to obtain relative root zone moisture, i.e., $S_{S M} / F C$. The scaled soil moisture is a dimensionless variable ranging from 0 to 1 . Throughout this paper this variable is used as a hydrological estimate of relative root zone soil moisture.

\subsection{Multi-objective calibration of the hydrologic model}

In this study, the model was calibrated for 320 gauged catchments. Daily inputs (precipitation, air temperature and potential evapotranspiration) were allowed to vary with elevation within a catchment, and the soil moisture accounting and snow accounting was performed independently in each elevation zone. However, the same model parameters were assumed to apply to all elevation zones of a catchment. From a total of 14 model parameters, 3 parameters were preset $\left(T_{R}=2^{\circ} \mathrm{C}, T_{S}=0^{\circ} \mathrm{C}, T_{M}=0^{\circ} \mathrm{C}\right)$ and 11 parameters (Table 1 ) were estimated by automatic model calibration. We used the shuffled complex evolution (SCE-UA) scheme of Duan et al. (1992) to calibrate the model parameters to observed runoff and snow cover. The objective function $\left(Z_{C}\right)$ to be minimised in the calibration involves three parts which are related to runoff $\left(Z_{Q}\right)$, snow cover $\left(Z_{S}\right)$ and a priori 
information about the distribution of each model parameter $\left(Z_{P}\right) . Z_{C}$ is the weighted mean of these parts:

$Z_{C}=w_{1} \cdot Z_{Q}+w_{2} \cdot Z_{S}+w_{3} \cdot Z_{P}$,

where the weights were set to $w_{1}=0.6, w_{2}=0.1$ and $w_{3}=0.3$ on the basis of test simulations. The test simulations consisted of sensitivity analyses that showed that a change in $w_{1}$ from 1.0 to 0.6 resulted in a variation of runoff model performance by only $4 \%$. At the same time, changing $w_{2}$ and $w_{3}$ resulted in more than a $10 \%$ increase in the snow model performance and in a significant improvement of the robustness of model parameters. These results indicate that the model results were only moderately sensitive to the choice of weights. The selection of weights is always subjective and depends on the relative importance attached to each component by the modeller. In this paper, we assigned the weights in way so that, on average, the runoff $\left(Z_{Q}\right)$, snow $\left(Z_{S}\right)$ and a priori $\left(Z_{P}\right)$ penalties contributed $65 \%, 5 \%$ and $30 \%$, respectively, to the final compound objective function $Z_{C}$.

The runoff objective function $Z_{Q}$ follows the relation proposed by Lindström (1997), which combines the NashSutcliffe coefficient $(M E)$ and the relative volume error $(V E)$ :

$Z_{Q}=(1-M E)+w_{4} \cdot|V E|$,

where

$$
\begin{gathered}
M E=1-\frac{\sum_{i=1}^{n}\left(Q_{\mathrm{obs}, \mathrm{i}}-Q_{\mathrm{sim}, \mathrm{i}}\right)^{2}}{\sum_{i=1}^{n}\left(Q_{\mathrm{obs}, \mathrm{i}}-\overline{Q_{\mathrm{obs}}}\right)^{2}}, \\
V E=\frac{\sum_{i=1}^{n} Q_{\mathrm{sim}, \mathrm{i}}-\sum_{i=1}^{n} Q_{\mathrm{obs}, \mathrm{i}}}{\sum_{i=1}^{n} Q_{\mathrm{obs}, \mathrm{i}}} .
\end{gathered}
$$

$Q_{\text {sim,i }}$ is the simulated streamflow on day $i, Q_{\mathrm{obs}, \mathrm{i}}$ is the observed streamflow, $\overline{Q_{\mathrm{obs}}}$ is the average of the observed streamflow over the calibration (or verification) period of $n$ days, and the weight $w_{4}$ was found in Parajka et al. (2005a) as $w_{4}=0.1$.

The snow objective function $Z_{S}$ compares the observed and simulated snow coverage. Observed snow coverage was estimated from daily grid maps constructed from the observed snow depth data. Simulated snow coverage was derived from the snow water equivalent simulated by the model for each elevation zone in the catchment. Snow simulations on a particular day were considered to be poor if the difference between simulated and observed snow coverage was greater than $50 \%$ of the catchment area. The 50\% threshold was determined in sensitivity analyses (not shown here) taking into account different areal arrangements of elevation zones in different catchments, where the sensitivity was assessed on the basis of model performance. The snow objective function $Z_{S}$ was then defined as the ratio of the number of days with poor snow cover simulation $\left(n_{p s}\right)$ to the total number of days in the simulation period:

$Z_{S}=\frac{n_{p s}}{n}$

The third term, $Z_{P}$, allows inclusion of an expert estimate about the a priori distribution of each parameter. In calibration procedures, the parameter values are usually bounded between two limits (Duan et al., 1992) and otherwise no a priori assumptions are made about the parameters. This implies that the a priori distribution of the parameters is a uniform distribution. We believe that it is possible to make a more informed guess about the shape of the a priori distribution and introduce a penalty function, $Z_{P}$, based on an a priori distribution for each parameter:

$$
\begin{aligned}
& Z_{P}=\sum_{j=1}^{k} \frac{f_{\max , j}-f_{j}\left(\frac{p_{j}-p_{l, j}}{p_{u, j}-p_{l, j}}\right)}{f_{\max , j}} \\
& f_{\max , j}=f_{j}\left(\frac{p_{\max , j}-p_{l, j}}{p_{u, j}-p_{l, j}}\right)
\end{aligned}
$$

where $p_{j}$ is the model parameter $j$ to be calibrated, $p_{l}$ and $p_{u}$ are the lower and upper bounds of the parameter space, respectively, $p_{\max }$ is the parameter value at which the a priori distribution is at a maximum and $k$ is the number of parameters to be calibrated. The probability density function of the Beta distribution $f$ is:

$$
\begin{aligned}
& f(x \mid u, v)=\frac{1}{B(u, v)} x^{u-1}(1-x)^{v-1} \\
& \text { for } 0<x<1, u>0, v>0
\end{aligned}
$$

with

$$
B(u, v)=\int_{0}^{1} x^{u-1}(1-x)^{v-1} d x=\frac{\Gamma(u) \Gamma(v)}{\Gamma(u+v)}
$$

where the values of $u, v, p_{l}, p_{u}$ and $p_{\max }$ have been taken from Merz and Blöschl (2004). In the absence of more detailed information we have chosen the same values of the $u, v, p_{l}, p_{u}$ and $p_{\max }$ for all catchments (Table 1). If more detailed information was available (for example from catchment attributes or from field studies), the limits and parameters of the Beta distributions for each model parameter could be assigned differently from catchment to catchment.

\subsection{Hydrologic model performance}

For the evaluation of the calibration and verification efficiencies the entire period of observation (1991-2000) was split into two periods: the calibration period from 1 November 1991 to 31 December 1995 and the verification period from 1 November 1996 to 31 December 2000. Warm up periods from January to October were used in both cases. We examined the model performance in terms of the efficiency of 
Table 2. Median and quantile difference ( $75 \%$ and $25 \%$ ) of runoff model efficiency $(M E)$, volume errors of runoff $(V E)$, snow cover simulations error $\left(Z_{S}\right)$ and correlation coefficient between the two soil moisture estimates $(r)$. Results are for 320 catchments. No assimilation of soil moisture data.

\begin{tabular}{lll}
\hline $\begin{array}{l}\text { Median/quantile } \\
\text { difference of }\end{array}$ & $\begin{array}{l}\text { Calibration period } \\
(1991-1995)\end{array}$ & $\begin{array}{l}\text { Verification period } \\
(1996-2000)\end{array}$ \\
\hline$M E[-]$ & $0.76 / 0.13$ & $0.73 / 0.19$ \\
$V E[\%]$ & $0.0 / 3.0$ & $1.9 / 9.3$ \\
$Z_{S}[\%$ of days] & $5.4 / 11.4$ & $4.2 / 10.3$ \\
$r[-]$ & $0.07 / 0.57$ & $0.12 / 0.50$ \\
\hline
\end{tabular}

the model of simulating runoff using the Nash-Sutcliffe coefficient ( $M E$, Eq. 4) and volume errors (VE, Eq. 5). We also examined the model performance in terms of the days of poor snow cover simulations $\left(Z_{S}\right.$, Eq. 6$)$. These performance measures have been evaluated independently for the calibration and the verification periods (Table 2).

Table 2 shows that the median of $M E$ over the 320 catchments in the calibration and verification periods is 0.76 and 0.73 , respectively. This means that the model performance decreases only slightly when moving from calibration to verification. The median of $V E$ in the calibration and verification periods is $0.0 \%$ and $1.9 \%$, indicating that both the calibration and verification is essentially unbiased. The median of the snow performance measure $Z_{S}$ is $5.4 \%$ in the calibration period and $4.2 \%$ in the verification period, which indicates that the model performance is even somewhat better in the verification period.

The spatial patterns of the runoff efficiencies $M E$ in the calibration (1991-1995) and verification (1996-2000) periods are presented in Fig. 2. Results indicate that there are regional differences in the model performance. In the western, alpine parts of Austria the simulation of runoff is generally better than in the eastern lowlands. The alpine catchments are wetter and snowmelt is more important than in the catchments of the east. Overall, the magnitudes of these model efficiencies are more favourable or similar to results from other regional studies published in the literature (e.g. Seibert, 1999; Perrin et al., 2001; Merz and Blöschl, 2004; Parajka et al., 2005a). This suggests that the parameter estimates are robust and that the model represents the hydrological balance of the catchments reasonably well.

\section{Comparison of soil moisture estimates}

We compared the relative soil moisture simulated by the hydrologic model with the SWI index estimated from the scatterometer data. Both estimates, notionally, represent root zone soil moisture. For the soil moisture simulations we used the parameter sets optimised for the calibration period

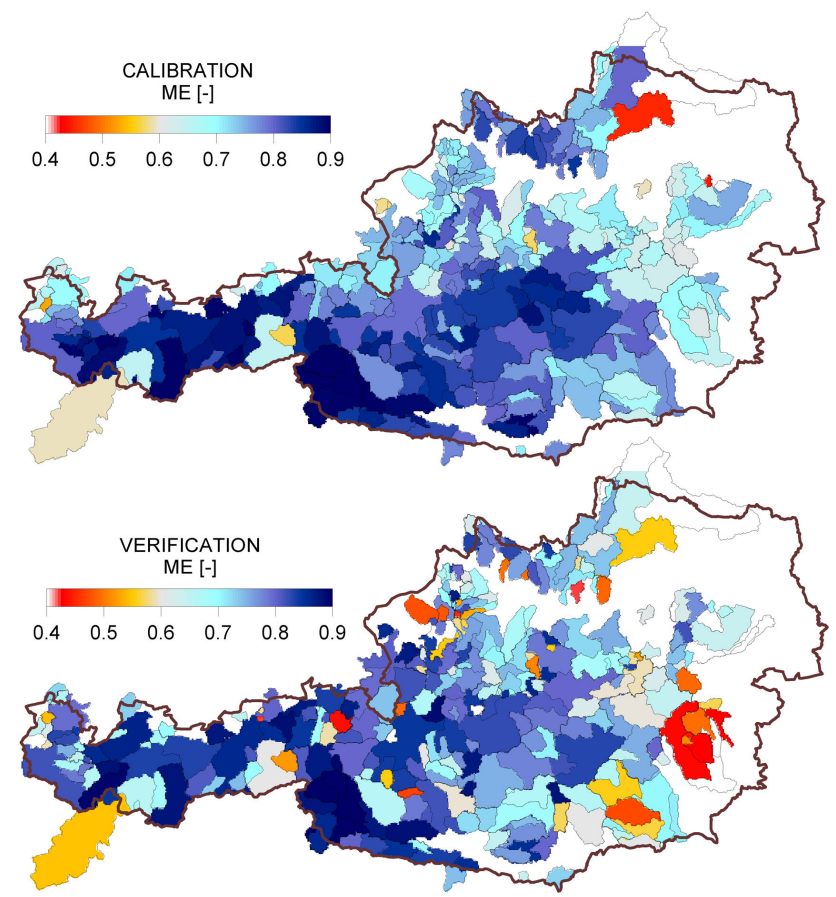

Fig. 2. Nash-Sutcliffe model efficiency $(M E)$ of daily runoff in the calibration (1991-1995) and verification periods (1996-2000). Calibration of hydrologic model was performed without the use of scatterometer soil moisture data.

(1991-1995) and simulated the daily water balance for all 320 catchments in the period 1991-2000. In each catchment, the soil moisture component was calculated separately for different elevation zones. Subsequently we constructed grid maps of soil moisture exhibiting subcatchment variability for each day of the selected simulation period. For the case of nested catchments, the soil moisture patterns of the smaller catchments were plotted on top of those of the larger ones. The scatterometer soil moisture values were assigned to the representative area (polygon) around the centroids (Fig. 1). For each day when scatterometer soil moisture data were available we plotted a grid map representing the regional variability of soil moisture. Examples of the spatial patterns of the relative soil moisture so estimated for two particular days are presented in Fig. 3.

The comparison of the spatial patterns of the hydrologic model and scatterometer soil moisture shows that for days with snow cover (e.g. Fig. 3, left) the scatterometer soil moisture is obviously not meaningful. The reason is that no soil moisture information can be obtained by remote sensing methods when snow covers the surface. Unfortunately, it is not possible to exclude snow observations based solely on the scatterometer data, which is why erroneous data are contained in the present version of the scatterometer soil moisture data base. A more plausible agreement between the spatial patterns is obtained for days without snow cover (e.g. Fig. 3, right) although the spatial patterns of the hydrologic 

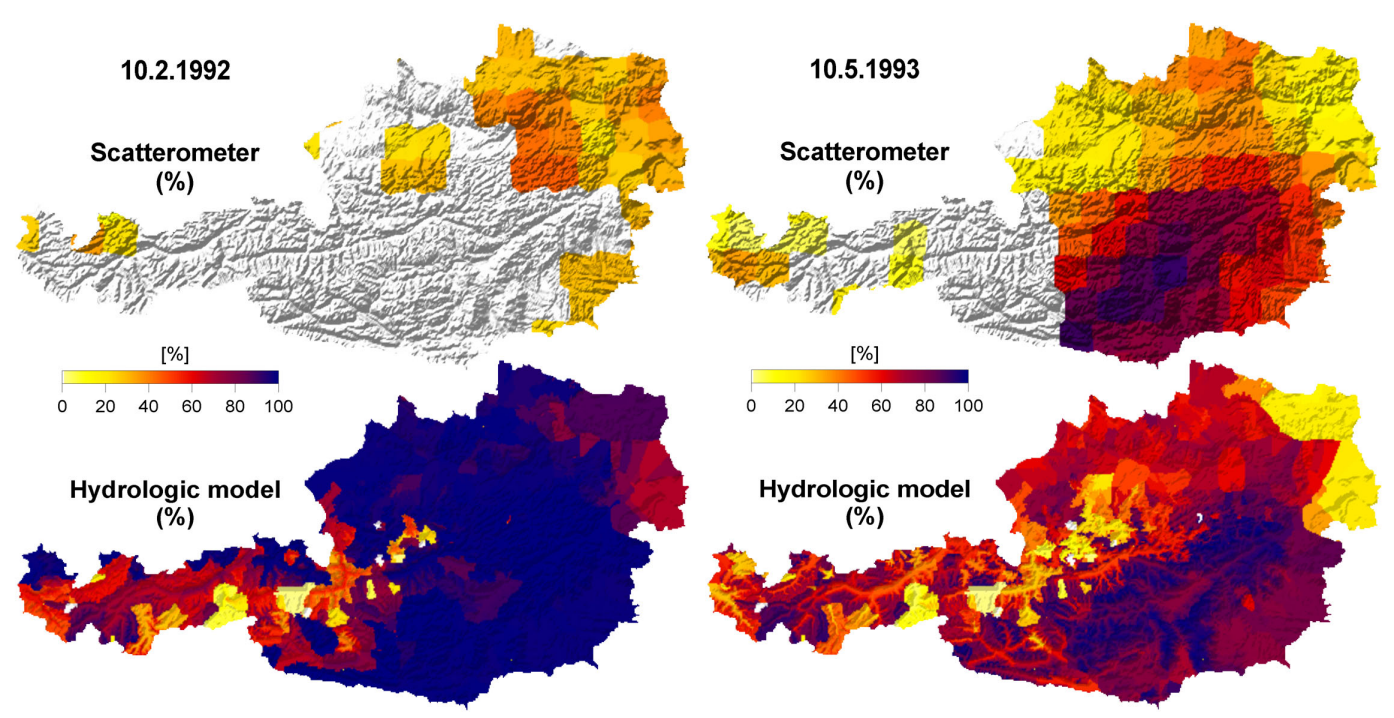

Fig. 3. Examples of spatial patterns of relative root zone soil moisture simulated by the hydrologic model (bottom) and estimated by the ERS scatterometer (top) for two particular dates: 10 February 1992 (left) and 10 May 1993 (right).

model soil moisture are much more spatially detailed. In the following analyses we therefore used the gridded snow depth information to exclude those soil moisture estimates that have been retrieved on days with existing snow cover (catchment mean snow depth $>0.1 \mathrm{~cm}$ ), and calculated the catchment average from the remaining soil moisture estimates simulated in different elevation zones for each particular day. We then compared the catchment mean soil moisture estimated by the hydrologic model with the scatterometer soil moisture of the nearest scatterometer retrieval point. The distance between the centroid of each catchment and the centroid of the scatterometer pixels was used for that purpose.

A demonstration of the temporal dynamics of the two different soil moisture sources is plotted in Fig. 4 for two catchments in the year 1992. Figure 4 top shows the comparison for the Weer catchment in Tirol. The mean catchment altitude of the catchment is $1735 \mathrm{~m}$. The comparison indicates that very little correlation exists between model-simulated and scatterometer-derived soil moisture. A much better agreement appears for the Pesenbach catchment (Fig. 4, bottom). The Pesenbach catchment is in Upper Austria and the mean catchment altitude is $569 \mathrm{~m}$. For the Pesenbach the correlation coefficient between the two soil moisture estimates is about 0.78 . The median and percentile difference $(75 \%-$ $25 \%)$ of the correlation coefficient $(r)$ over all 320 catchments is presented in Table 2. The median of $r$ indicates that for the majority of the catchments there is very little correlation between scatterometer and model soil moisture estimates in both the calibration and verification periods. However significant regional differences exist.

The spatial patterns of the overall agreement between the two soil moisture sources, in terms of the correlation coeffi- cient, are presented in Fig. 5. Figure 5 top and bottom show the correlations for the calibration period (1991-1995) and verification period (1996-2000), respectively. The spatial patterns of the correlation coefficient, especially for the calibration period, exhibit a distinct boundary between the alpine region and the lower parts of Austria. In the Alpine region, the correlations are poor and even negative. In the northern prealpine and northern/eastern lowland areas the relationship between the two different soil moisture estimates seems to be significant.

These results indicate that in the alpine regions with complex terrain it is difficult to derive regionally consistent soil moisture estimates from the scatterometer data and the hydrologic model simulations. In the flatlands, the estimates seem to be much more accurate. Part of the poor correlations in the Alps may be due to the rugged terrain and forest cover which may make the scatterometer data less accurate than in the flatlands. The low correlations may also be due to only using the summer scatterometer data. This will reduce the seasonal sample variance which, with a given error variance, will decrease the correlation coefficient. Clearly, the soil moisture estimates from the hydrological simulations are also associated with considerable uncertainty. One would, however, not expect major differences in the uncertainty between the Alpine and lowland parts of Austria.

\section{Scatterometer soil moisture assimilation}

In order to reconcile the two soil moisture estimates we assimilated the scatterometer data in the calibration phase of the hydrological model. We extended the multi-objective 

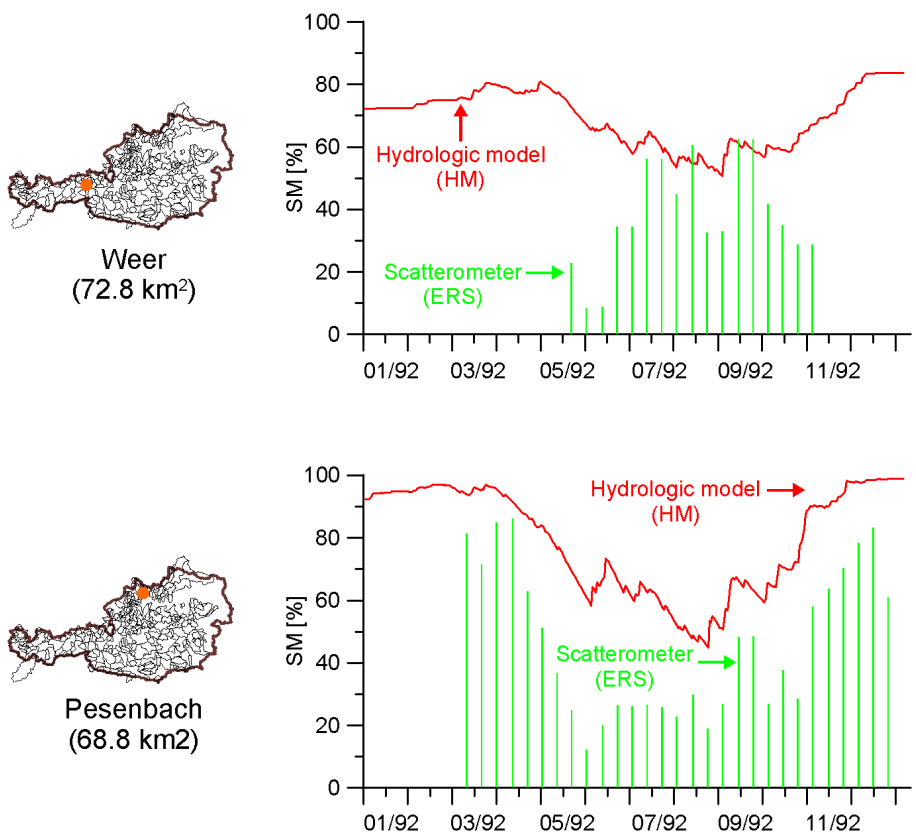
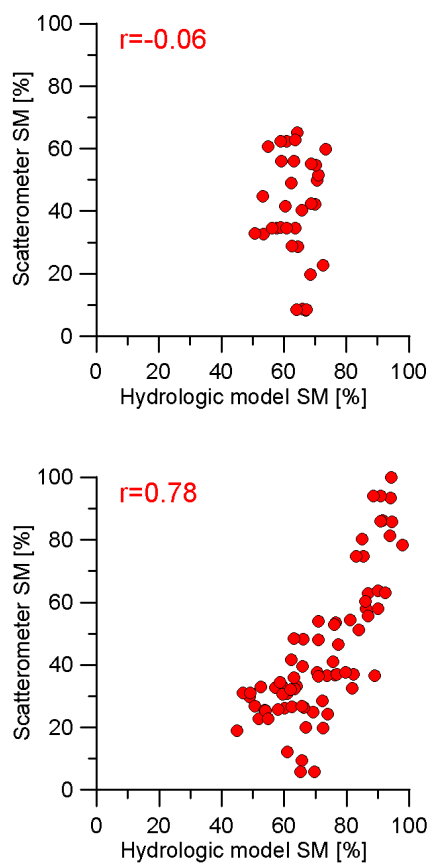

Fig. 4. Comparison of relative soil moisture simulated by the hydrologic model (HM) and derived from the scatterometer (ERS). Example for two catchments, Weer catchment (top) and Pesenbach catchment (bottom). Scatterplots (right) show the correlation ( $r$ ) between different soil moisture estimates obtained for days without snow cover in the period 1992-2000.

calibration approach presented in the previous section (Eq. 2) by using the following objective function:

$Z_{A}=(1-r) \cdot Z_{C}$,

where $r$ is the correlation coefficient between soil moisture estimated from the scatterometer data and simulated by the hydrologic model, and $Z_{C}$ represents the compound objective function defined by Eq. (2). We selected the correlation coefficient $r$ as a measure of similarity between the two soil moisture estimates because it allows a comparison of the temporal dynamics of the two variables irrespective of their absolute magnitudes and possible intercepts in their relationship. The form of the compound objective function has been chosen subjectively in order to reflect the trade-off between the multiple objectives. As the objective function is minimised, large correlation coefficients will be favoured in the calibration process. Based on the soil moisture comparison above, the correlation coefficient between the soil moisture estimates was calculated only for days when no snow cover was observed.

The model efficiencies obtained in the data assimilation are presented in Table 3. The medians of the runoff efficiency $M E$ over the 320 catchments in the calibration and verification periods are 0.75 and 0.72 , respectively. This is only slightly poorer than the efficiencies obtained without data assimilation (Table 2). The median of the volume error $V E$ in the calibration and verification periods is $0.1 \%$ and $0.4 \%$, respectively, indicating that the data assimilation in the cali- bration and verification periods is essentially unbiased. The percentile difference, i.e. the scatter between the catchments, of the volume errors do increase when scatterometer data are assimilated. The median of the snow performance measure $Z_{S}$ in the calibration period is $5.1 \%$ and in the verification period it is $3.9 \%$, which suggests that this model performance is even somewhat better than that obtained without data assimilation.

The spatial patterns of the $M E$ model performance in the calibration and verification periods are presented in Fig. 6 . These patterns are similar to those obtained in simulations without the assimilation of scatterometer data (Fig. 2). Again, in the verification period the runoff model efficiency is somewhat lower than in the calibration period. This indicates that scatterometer assimilation into the model calibration does not significantly decrease the runoff model efficiency.

Very significant differences between the cases with and without assimilation do occur, however, in the correlation coefficients between the soil moisture estimates (Fig. 7). Assimilation of scatterometer data in the model calibration increases the correlations dramatically. This is not surprising, of course. Significant improvements occur, especially, in the western, Alpine, part of Austria, but the correlations also increase in the lowland areas. Table 3 suggests that the increase in the median of the correlation coefficient is from 0.07 to 0.26 (calibration period) and from 0.12 to 0.17 (verification period). Also, the quantile differences decrease which 


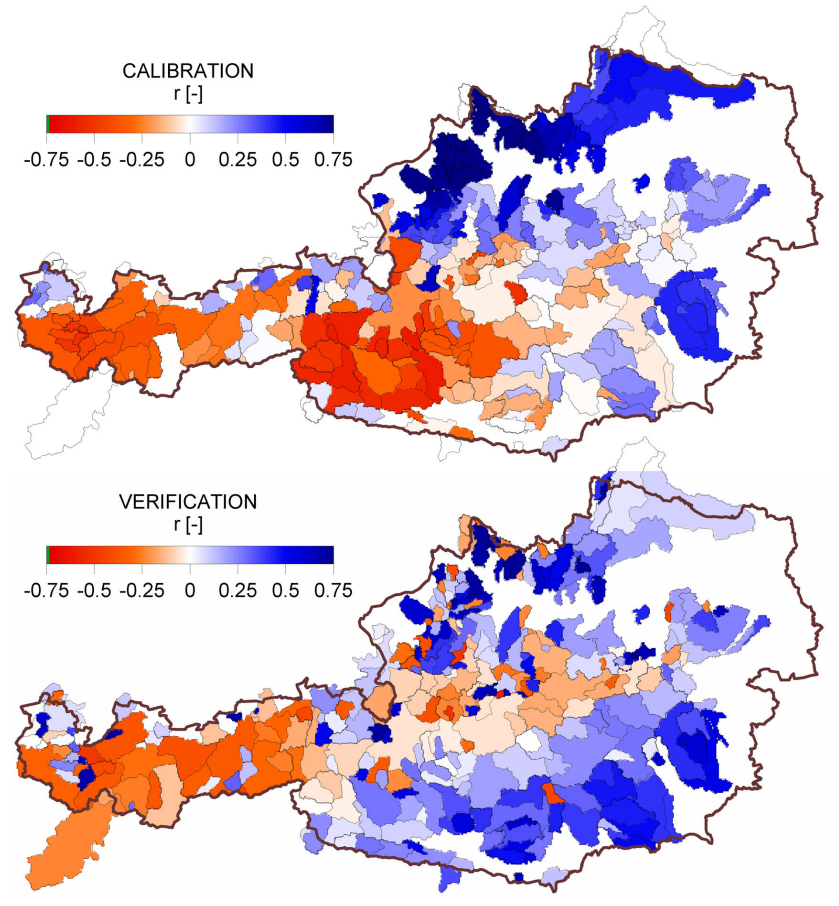

Fig. 5. Spatial patterns of the correlation coefficient, $r$, between soil moisture simulated by the hydrologic model and soil moisture derived from the ERS scatterometer in the calibration (19911995) and verification (1996-2000) periods. No assimilation of scatterometer soil moisture data.

indicates that the match of the two soil moisture sources is more consistent throughout Austria.

The regional difference in soil moisture correlations indicates that for northern prealpine regions and lowlands the soil moisture dynamics of the hydrological model agree well with the satellite estimates of soil moisture, even in the validation period. For these areas it is possible to reconcile the two sources of soil moisture estimation. The soil moisture correlations in the alpine areas are somewhat better than without data assimilation, however, the relationship is still poor.

Including the scatterometer data in the calibration of the hydrologic model changes the temporal soil moisture dynamics simulated by the hydrologic model. Figure 8 presents an example. Figure 8 top shows the simulations for the Weer catchment where, previously, no correlations between two soil moisture estimates were found. Assimilating the scatterometer data improves the soil moisture correlation from -0.06 to more than 0.54 . Figure 8 bottom shows the soil moisture time series for the Pesenbach catchment. For this catchment, the correlation coefficient between the two soil moisture estimates increases from 0.78 to 0.86 . In the two examples, the main effect is that the scatterometer data assimilation decreases the calibrated value of the field capacity, $F C$, of the model. The relative soil moisture (i.e. soil moisture scaled by the field capacity hence fluctuates strongly when

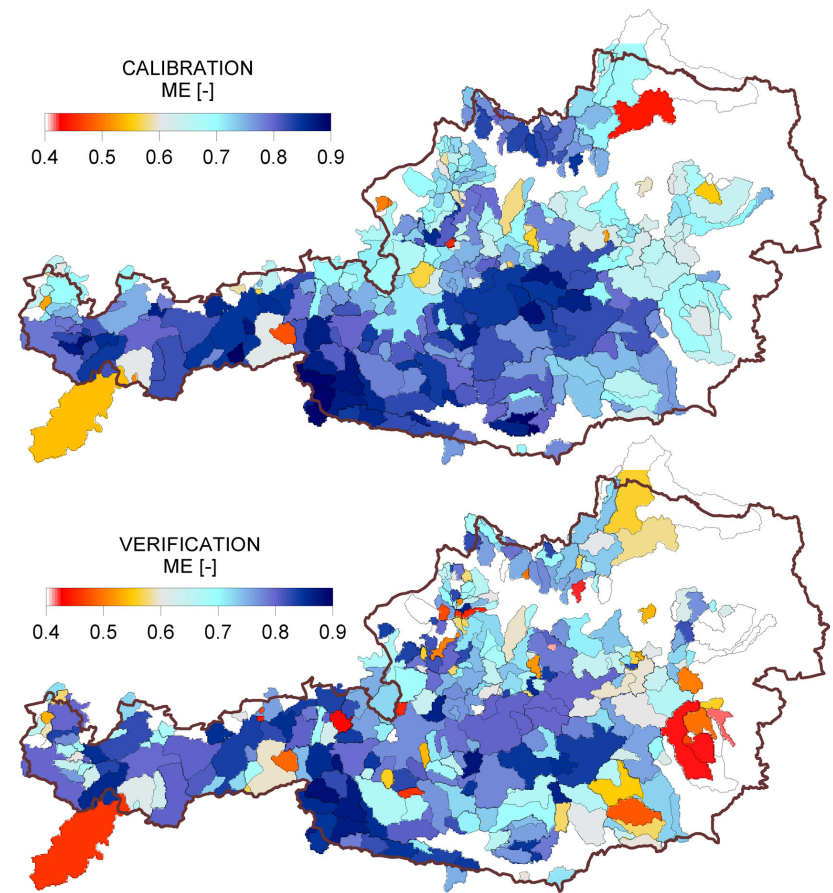

Fig. 6. Nash-Sutcliffe model efficiency $(M E)$ of daily runoff in the calibration (1991-1995) and verification periods (1996-2000). Scatterometer soil moisture data have been assimilated in the calibration phase of the hydrologic model.

Table 3. Median and quantile difference (75\%-25\%) of runoff model efficiency $(M E)$, volume errors of runoff $(V E)$, snow cover simulations error $\left(Z_{S}\right)$ and correlation coefficient between the two soil moisture estimates $(r)$. Results are for 320 catchments. Assimilation of scatterometer soil moisture data.

\begin{tabular}{lll}
\hline $\begin{array}{l}\text { Median/quantile } \\
\text { difference of }\end{array}$ & $\begin{array}{l}\text { Calibration period } \\
(1991-1995)\end{array}$ & $\begin{array}{l}\text { Verification period } \\
(1996-2000)\end{array}$ \\
\hline$M E[-]$ & $0.75 / 0.13$ & $0.72 / 0.18$ \\
$V E[\%]$ & $-0.1 / 6.2$ & $0.4 / 12.0$ \\
$Z_{S}[\%$ of days] & $5.0 / 10.8$ & $3.9 / 10.6$ \\
$r[-]$ & $0.26 / 0.37$ & $0.17 / 0.40$ \\
\hline
\end{tabular}

scatterometer data are assimilated. Interestingly, for both example catchments, the data assimilation does not change the model efficiency with respect to daily runoff.

\section{Hydrologic model performance for ungauged catch- ments}

In this section we tested the potential of assimilating scatterometer data for improving hydrological predictions in ungauged catchments. As the scatterometer data are available for both gauged and ungauged catchments, it may be possible 


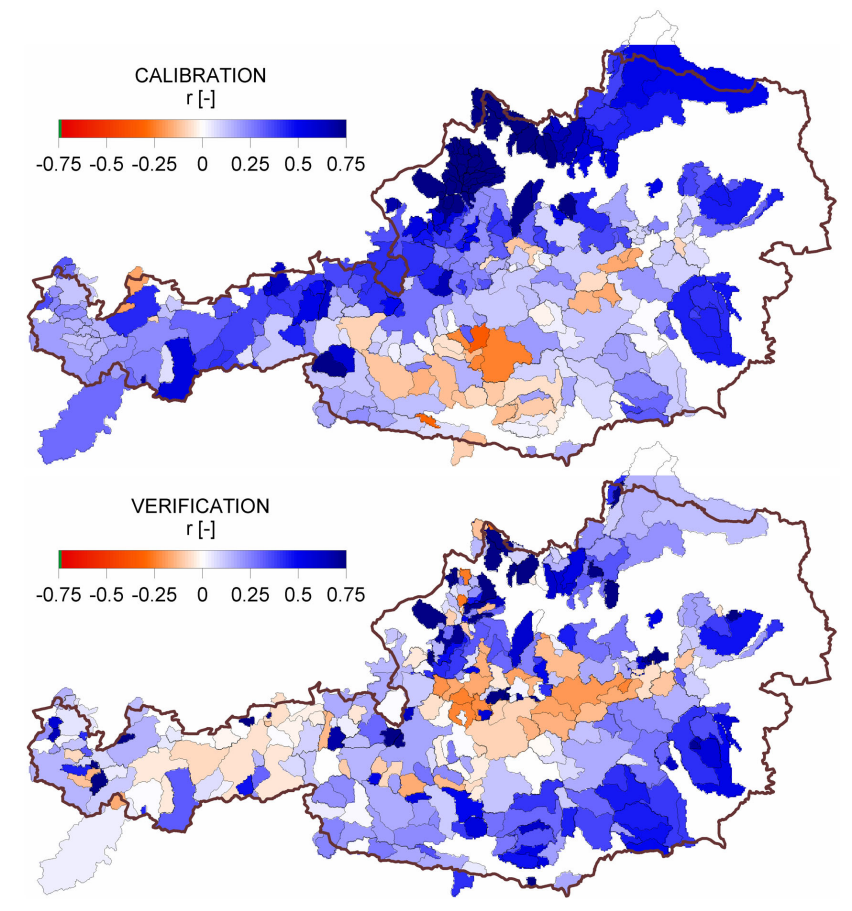

Fig. 7. Spatial patterns of the correlation coefficient, $r$, between soil moisture simulated by the hydrologic model and soil moisture derived from the ERS scatterometer in the calibration (1991-1995) and verification (1996-2000) periods. Scatterometer soil moisture data have been assimilated in the calibration phase of the hydrologic model.

to extract useful information for simulations in ungauged catchments. Estimation of daily runoff and soil moisture in ungauged catchments was evaluated for two cases. In the first case we only used observed snow cover data and the regionalised information about the model parameters for the prediction at ungauged sites. In the second case we additionally used the information about the soil moisture state obtained from the scatterometer data. For both cases, we calibrated the hydrologic model without the information of locally measured runoff using the following objective function $Z_{U}$ :

$Z_{U}=w_{5} \cdot(1-r)+w_{6} \cdot Z_{S}+w_{7} \cdot Z_{P}$

where $r$ is the correlation coefficient between model simulated soil moisture and scatterometer derived soil moisture for days without observed snow cover, $Z_{S}$ represents the agreement between observed and simulated snow cover (Eq. 6) and $Z_{P}$ (Eq. 7) is the penalty based on an a priori distribution for each parameter. For the ungauged case prediction, we did not apply a uniformly predefined parameter distribution in each of the 320 catchments (as in the multiple objective calibration), but we constrained each parameter in each catchment separately, based on information obtained from parameter transposition from neighbouring catchments using the kriging method. The transposition of the model
Table 4. Median and quantile difference $(75 \%-25 \%)$ of model efficiency of runoff $(M E)$, volume errors of runoff $(V E)$ and correlation coefficients between the two soil moisture estimates $(r)$ calculated for the ungauged catchment case. Results are for 320 catchments. No assimilation of soil moisture data.

\begin{tabular}{lll}
\hline $\begin{array}{l}\text { Median/quantile } \\
\text { difference of }\end{array}$ & $\begin{array}{l}\text { Calibration period } \\
(1991-1995)\end{array}$ & $\begin{array}{l}\text { Verification period } \\
(1996-2000)\end{array}$ \\
\hline$M E[-]$ & $0.65 / 0.16$ & $0.64 / 0.19$ \\
$V E[\%]$ & $-1.4 / 16.4$ & $-1.0 / 15.5$ \\
$Z_{S}[\%$ of days] & $4.6 / 11.3$ & $4.6 / 10.7$ \\
$r[-]$ & $0.11 / 0.54$ & $0.16 / 0.40$ \\
\hline
\end{tabular}

Table 5. Median and percentile difference (75\%-25\%) of model efficiency of runoff $(M E)$, volume errors of runoff $(V E)$ and correlation coefficients between the two soil moisture estimates $(r)$ calculated for the ungauged case. Results are for 320 catchments. Assimilation of scatterometer soil moisture data.

\begin{tabular}{lll}
\hline $\begin{array}{l}\text { Median/quantile } \\
\text { difference of }\end{array}$ & $\begin{array}{l}\text { Calibration period } \\
(1991-1995)\end{array}$ & $\begin{array}{l}\text { Verification period } \\
(1996-2000)\end{array}$ \\
\hline$M E[-]$ & $0.61 / 0.19$ & $0.59 / 0.21$ \\
$V E[\%]$ & $-4.2 / 15.8$ & $-3.1 / 16.5$ \\
$Z_{S}[\%$ of days] & $4.4 / 11.4$ & $4.5 / 10.3$ \\
$r[-]$ & $0.27 / 0.36$ & $0.17 / 0.36$ \\
\hline
\end{tabular}

parameters was as in Parajka et al. (2005). The weights in Eq. (12) were examined in test simulations (not shown here), and were set to $w_{6}=1.0$ and $w_{7}=1.0$. The distinction between the two cases was the weight $w_{5}$. For the second case, where we tested the potential of soil moisture scatterometer data we set the weight $w_{5}$ to 0.2 . In the first case we removed the influence of this term by setting $w_{5}$ to 0.0 .

The evaluation of the model performance was as in Parajka et al. (2005). We treated one gauged catchment as ungauged and simulated the water balance dynamics using parameters estimated without the local runoff measurements. Next, we estimated the model performance by comparing the simulated and observed hydrographs as well as the correlation between simulated and scatterometer derived soil moisture. We repeated the analysis for each catchment in turn and calculated the statistics of these error measures for all catchments. The comparison of these error measures with those for the locally calibrated case, both for the calibration and verification periods, indicates what decrease of model performance one would have to expect when moving from gauged to ungauged catchments. This decrease we term the spatial loss in model accuracy.

The results of model performance in ungauged sites is presented in Tables 4 and 5. Table 4 gives the model efficiencies 

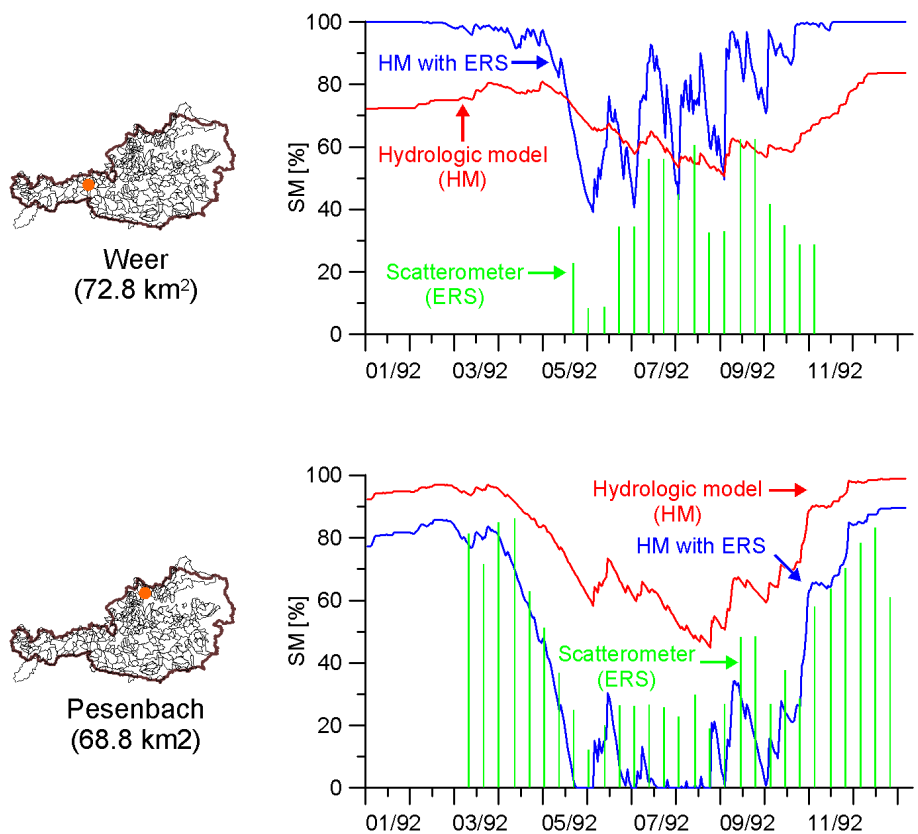
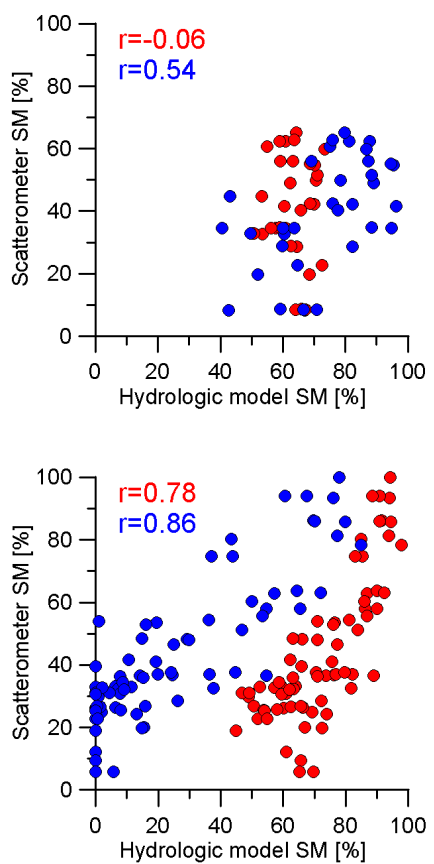

Fig. 8. Comparison of relative soil moisture simulated by the hydrologic model (HM) and derived from the scatterometer (ERS). Example for two catchments, Weer catchment (top) and Pesenbach catchment (bottom). Scatterplots (right) show the correlation $(r)$ between different soil moisture estimates obtained for days without snow cover in the period 1992-2000. Red colour represents the soil moisture simulations using the model parameters obtained without the soil moisture data assimilation, blue colour represents the soil moisture simulations using the model parameters obtained with soil moisture data assimilation.

for ungauged catchments without the use of scatterometer data. The median of the runoff model efficiency $(M E)$ was 0.65 in the calibration and 0.64 in the verification periods. This indicates that the spatial loss in $M E$ was 0.11 in the calibration and 0.09 in the verification periods, when compared to local calibration including at site runoff measurements (Table 2). The median of runoff volume errors (VE) is slightly negative in the calibration and verification periods which suggests a slight underestimation of runoff. The median of the correlation coefficients yields 0.11 in the calibration and 0.16 in the verification periods which shows poor agreement between model simulated and satellite-derived soil moisture estimates.

Table 5 shows the runoff model performance when the scatterometer data were assimilated in the ungauged catchment predictions. The medians of the runoff $M E$ for the calibration and verification periods is 0.61 and 0.59 , respectively. This indicates that the data assimilation decreases runoff simulation performance as compared to the case where no scatterometer data are assimilated (Table 4). In the calibration period the decrease is from 0.65 to 0.61 and in the verification period the decrease is from 0.64 to 0.59 . In fact, the decrease in runoff model performance is larger than for the gauged catchment cases (Tables 2 and 3). The procedure hence does not seem to extract useful information from the scatterometer data in ungauged catchments. The median of runoff volume errors, $V E$, is $-4.2 \%$ in the calibration and $-3.1 \%$ in the verification periods. This indicates a slight underestimation of runoff in both periods.

As would be expected, the correlation coefficients between the soil moisture simulated by the hydrologic model and derived from the scatterometer data increases if scatterometer data are assimilated. In the calibration period, the increase is significant (from 0.11 to 0.27 ). In the verification period, however, the increase is slim (from 0.16 to 0.17 ). Clearly, for the verification period no scatterometer data have been assimilated and the information does not seem to carry over from the calibration to the verification period.

The relative changes in model performance due to assimilating scatterometer data for ungauged catchments are shown in Fig. 9 top. Blue colours relate to catchments where the runoff model efficiency improves when scatterometer data are assimilated. Red and yellow colours relate to catchments where the runoff model efficiency decreases. Most catchments are red or yellow. This indicates that assimilating scatterometer data does not improve runoff simulations in ungauged catchments. In fact, the runoff simulation performance tends to decrease.

Figure 9 bottom shows the relative changes in the correlations between the soil moisture estimates from scatterometer data. Again, blue colours relate to catchments where the correlations increase, red and yellow colours relate to 


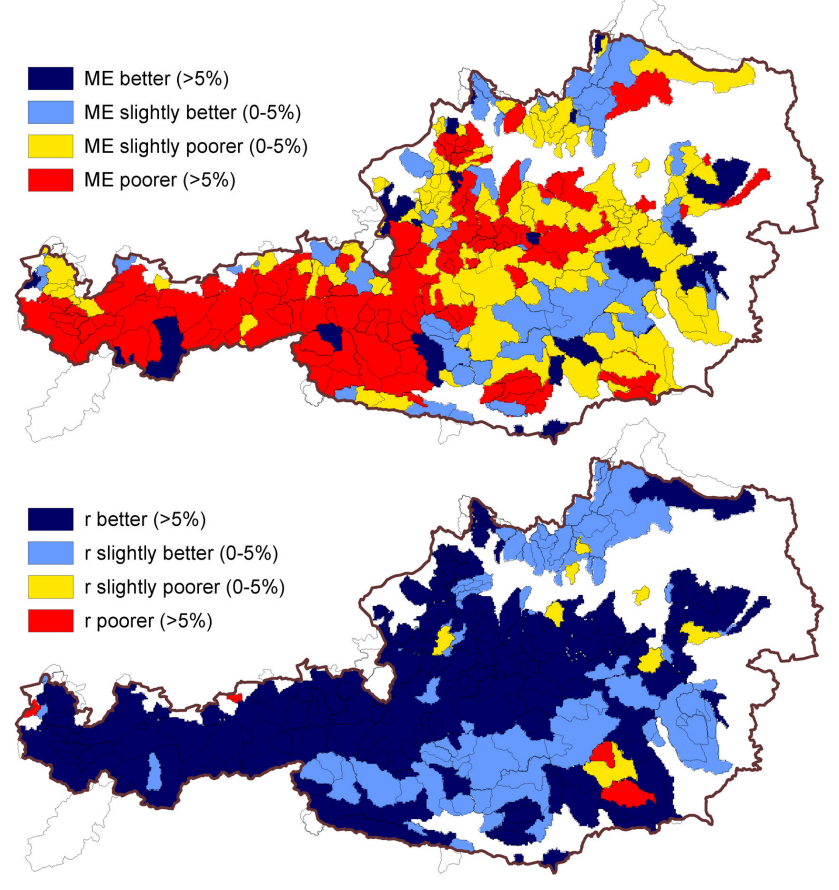

Fig. 9. Relative change in runoff model efficiency $(M E)$ and in the relationship between scatterometer and hydrologic model soil moisture estimates when scatterometer data are used in the ungauged sites simulations. The relationship between the two soil moisture estimates is represented by the correlation coefficient $(r)$. Calibration period (1991-1995).

catchments where the correlations decrease. In terms of soil moisture simulations the correlations do increase in almost all catchments. While a tighter relationship between the two soil moisture estimates is no surprise, it does allow for more consistent soil moisture estimates in ungauged catchments.

\section{$7 \quad$ Discussion and conclusions}

The comparison of the two different soil moisture estimates indicates that their spatial and temporal dynamics are quite different. Because of this, the potential of improving runoff simulations by assimilating scatterometer data into the hydrological model is limited in the study region examined here. The most noticeable differences were observed between the alpine regions and the flatlands. Results showed that there is a strong decrease in the correlation between the soil moisture estimates in regions with mean elevations of more than $600 \mathrm{~m}$ a.s.l. and large topographical variability. There are a number of potential sources of these differences.

The first source of disagreement may be related to problems with the scatterometer retrieving algorithm in alpine regions. Retrieval of soil moisture from scatterometer data performs best over flat to gently undulating regions with low vegetation cover (grassland, crops, etc.). Retrieval is

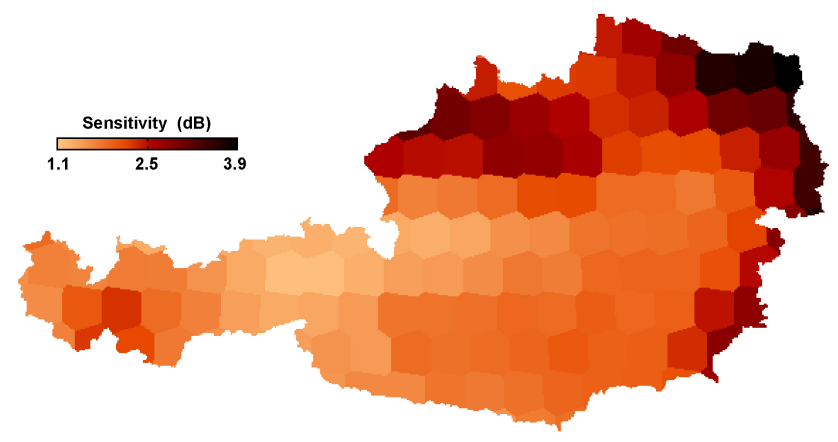

Fig. 10. Scatterometer sensitivity to soil moisture in $\mathrm{dB}$ the month July, when vegetation is most dense in Austria. The sensitivity is defined as the difference in backscatter between the driest and wettest observed soil conditions in the nine year period (1992-2000), corrected for the seasonal vegetation dynamics.

much more limited over densely forested terrain, rock outcrops or urban areas which are all characterized by very stable and high backscatter in C-band (Wagner et al., 1999a). Therefore, with increasing percentage of forest cover, rock outcrops or urban area within one scatterometer pixel one would expect the soil moisture sensitivity to decrease. Figure 10 shows the sensitivity of the backscattering coefficient to soil moisture changes, expressed in decibels, for July, when vegetation is most dense in Austria. The sensitivity is defined as the difference in backscatter between the driest and wettest observed soil conditions in the nine year period (1992-2000), corrected for the seasonal vegetation dynamics. As expected, the highest sensitivity can be observed over the agriculturally-dominated Austrian lowlands with values of up to $4 \mathrm{~dB}$, although this is a much lower sensitivity compared to grassland regions, where sensitivities up to $8-10 \mathrm{~dB}$ can be observed. Over the densely forested Austrian Alps the sensitivity is significantly lower with values ranging from 1 to $2 \mathrm{~dB}$. This value is not much larger than the typical noise level of the scatterometer data over these regions, which is about $0.3 \mathrm{~dB}$. This shows that retrieval is expected to perform significantly better over the lowlands than over the mountain regions.

To better understand the potential controls on the consistency of the soil moisture patterns we plotted the correlation coefficients of soil moisture from Fig. 5a against a number of landscape characteristics. Figure 11a shows the correlation coefficients plotted versus the standard deviation of elevation within each scatterometer polygon. There is an apparent relationship with low relief areas exhibiting much stronger correlations than high relief areas. Figure $11 \mathrm{~b}$ shows the correlation coefficients plotted versus the percent forest area of each scatterometer polygon. There is a clear trend of the upper envelope. Open areas may show large correlation coefficients but, as the forest cover increases, the maximum correlations that can be obtained decrease. This is related to the decrease of scatterometer sensitivity with percent forest 

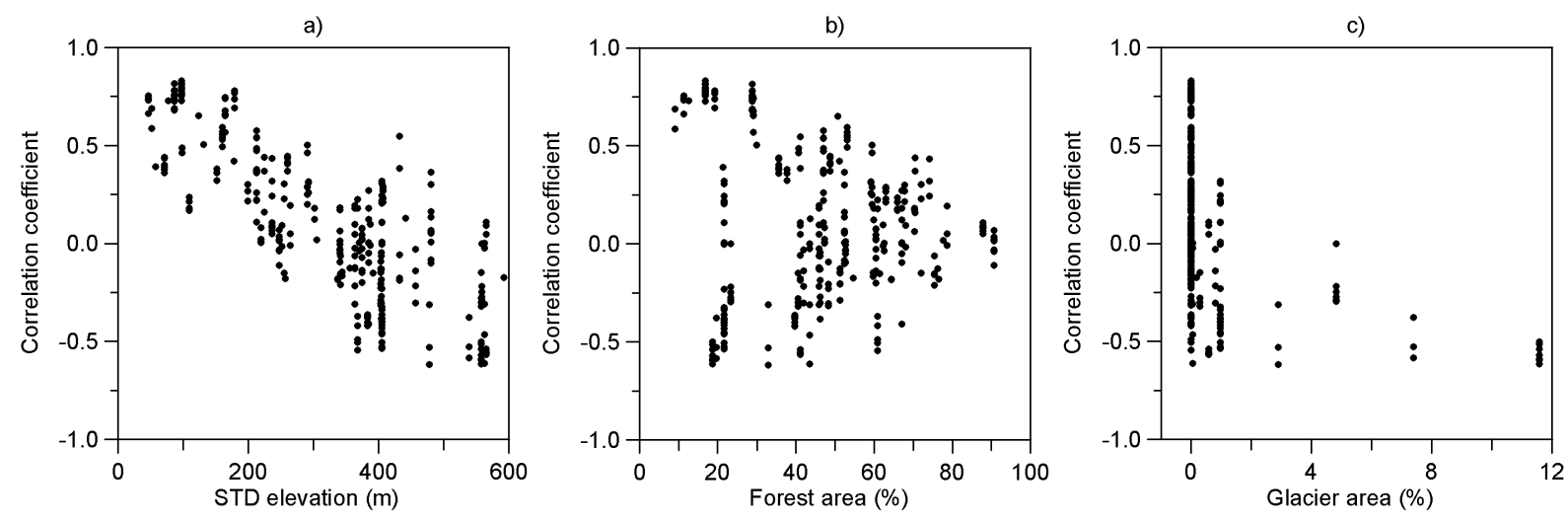

Fig. 11. Correlation coefficient, $r$, between soil moisture simulated by the hydrologic model and soil moisture derived from the ERS scatterometer in the calibration period (1991-1995) as per Fig. 5a plotted versus (a) standard deviation of elevation within each scatterometer polygon; (b) percent forest area of each scatterometer polygon; (c) percent glacier area of each scatterometer polygon.

cover. However, apparently, there are other controls as some of the polygons with little forest cover show very low correlations. These are the high alpine areas where mountain pastures, rocks and glaciers prevail. Figure 11c shows the correlation coefficients plotted versus percent glacier of each polygon. The polygons with a large proportion of glacier always show negative correlations. Clearly, glaciers limit the retrieval of soil moisture.

The second source of disagreement may stem from the hydrological model. The hydrological model performs best, in terms of simulating runoff, in the alpine areas and poorest in the lowlands. One would therefore not necessarily expect lower performance in terms of simulating soil moisture in the mountains as compared to the low lands. However, the main control of runoff in the mountains is snow rather than soil moisture, so there is the possibility that soil moisture is represented poorly. The strong association of the negative correlations with glacier area in Fig. 11c is, in fact, an indication that the hydrological model does not simulate soil moisture well in the high alpine catchments where glacier runoff is important. No glacier component has been included in the hydrological model and snow fall and snow depletion on glaciers are represented by the snow component of the model.

The differences between the two soil moisture estimates may also be related to the spatial variability of the forcing climatic variables (precipitation, air temperature, solar radiation etc.) in alpine regions. Alpine catchments tend to have a much larger altitudinal range than flatland catchments which may result in a much larger within-catchment variability of soil moisture controls and hence soil moisture. Figure 12 shows an analysis of the spatial within-catchment variability of simulated soil moisture, normalised by the temporal variability of catchment soil moisture within the simulation period. The spatial variability is indeed much larger in the alpine catchments than it is in the lowlands. In the Alps the

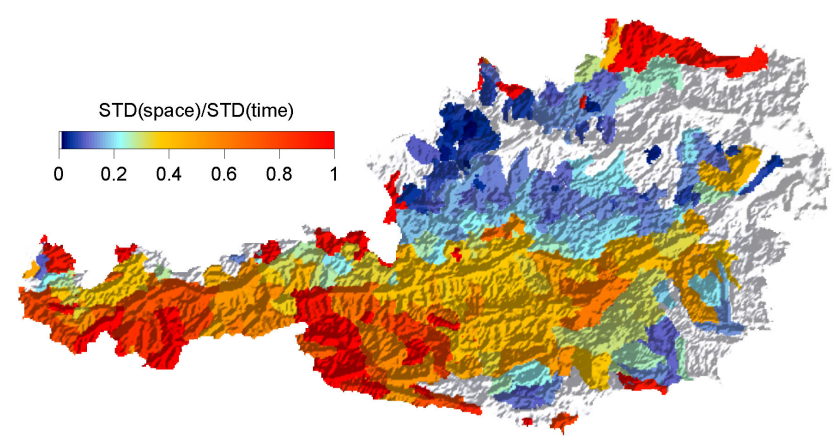

Fig. 12. Ratio of the standard deviation of soil moisture within a catchment (variability in space) and the standard deviation of catchment soil moisture within the period 1991-2000 (variability in time).

ratio is more than six times that in the lowlands. The pattern is very similar to those of the correlation coefficients between soil moisture simulated by the hydrologic model and soil moisture derived from the ERS scatterometer data (Fig. 5). It is also similar to the improvement in runoff model efficiency when scatterometer data are used in the ungauged sites simulations (Fig. 9 top). The low correlation coefficients of the hydrologically modelled and scatterometer soil moisture are co-located with the large spatial within-catchment variability in the Alps. On the other hand, the large correlation coefficients are co-located with the small spatial within-catchment variability in the lowlands. The similarity of the patterns suggests that the spatial within-catchment variability does indeed strongly affect the correlation between the two soil moisture estimates.

As soil moisture cannot be retrieved by the scatterometer when snow is on the ground, in the comparisons of this paper, $S W I$ values have only been used for those dates where the snow depth data indicated snow free ground. There 
are alternatives of how to mask snow cover effects on the scatterometer data. To examine the effect of the masking we tested the correlation between the two soil moisture estimates under different masking criteria. The correlations slightly improved when the scatterometer surface data, $m_{s}$, were masked rather than the $S W I$ data. The correlation improved further when $S W I$ data were calculated for the days of scatterometer acquisitions instead at regular 10 days intervals. This is because of the limited scatterometer coverage which has a negative impact on the quality of the SWI. There may therefore be potential in improving the masking criteria. There is also potential in spatially varying the time constant of the filter or pseudo diffusivity to account for the differences in the penetration depth of the scatterometer data and the depth of the top soil layer in the hydrological model. In this paper a value of $T=20$ days has been selected. The time constant would be expected to depend on soil depth which is likely smaller in the Alps than it is in the flatlands. More detailed soils data, however, is needed to constrain this parameter.

A problem particular to the Austrian situation is the very low number of scatterometer acquisitions due to operation conflicts with the Synthetic Aperture Radar (SAR) on board of ERS-1 and ERS-2. For the period used in this paper, scatterometer acquisitions were taken in only $17-40 \%$ of all satellite overpasses. Considering, in addition, the lengthy snow and frost period in the Austrian Alps the number of available data is much less than over most land surfaces worldwide. Still, also the data acquired over the mountain regions were considered in this study to examine how much information relevant to soil moisture is contained in the scatterometer data under such difficult conditions.

Overall, the assimilation of scatterometer data into the calibration of the hydrologic model has been found to improve the relationship between the two soil moisture estimates, without any significant decrease in runoff model efficiency. However, it should be noted that, in the alpine regions, the increase in soil moisture correlation was not very significant and the soil moisture relationship was still rather poor. The calibration using the scatterometer data has changed the temporal dynamics of soil moisture especially in the alpine regions. The temporal variability of soil moisture has increased mainly due to a decrease in the field capacity model parameter, $F C$, and a change in the nonlinearity parameter, $\beta$. Interestingly, the change in model parameters does not affect much the overall model performance with respect to measured runoff. These results point to the potential of scatterometer data assimilation in regional water balance simulations especially in terms of reducing the degrees of freedom in the calibration. Reconciling the two different soil moisture estimates for gauged catchments may be of value if one is interested in the temporal dynamics of soil moisture in regions with small topographical variability and low vegetation.

The runoff model efficiencies in the ungauged case predictions without using scatterometer data are similar to results obtained in other regionalisation studies (e.g. Parajka et al., 2005a). The use of scatterometer data for ungauged catchments decreases the runoff model performance significantly in the alpine catchments. This is apparently related to the low signal to noise ratio of the scatterometer data in the Alps. The relationship between the two soil moisture estimates is poorly defined. There are a number of lowland catchments where the ungauged catchment performance is increased as a result of assimilating the scatterometer data. In almost all catchments, the use of scatterometer data improves the consistency between the scatterometer data and the hydrologic model estimates at ungauged sites both for the calibration and the verification periods. It is hence possible to reconcile the two sources of soil moisture but there is little value of assimilating scatterometer data for simulating runoff, neither in gauged nor in ungauged catchments. However, if soil moisture is the main interest there may be value in reconciling the two soil moisture estimates because of the different error structures. As in the gauged catchment case, this applies to regions with small topographical variability and low vegetation.

Satellite data are sometimes recommended to assist hydrological simulations in ungauged catchments (Blöschl, 2005). There are a number of studies that report on close correlations between observed runoff and satellite soil moisture data. Scipal et al. (2005), for example, found a high correlation $\left(R^{2}>0.85\right)$ between basin-averaged soil moisture data from the scatterometer and measured runoff of the Zambezi River in south-eastern Africa. However, the analyses in this paper indicate that the correlations may much lower under more difficult conditions and for smaller catchment scales. Also, the existence of correlations does not necessarily imply improvements of runoff simulations. Indeed, there is very little evidence in the literature to indicate that soil moisture satellite data may assist in improving runoff simulations and/or forecasts both in gauged and ungauged catchments. There are, of course, numerous other reasons for using satellite data in hydrology. It is also likely that new developments will increase the usefulness of soil moisture information from satellites for hydrological purposes. As new sensors are becoming available one would expect the soil moisture information content of scatterometer data to improve. The higher spatial resolution $(25 \mathrm{~km})$ provided by the successor of the ERS scatterometer, the Advanced Scatterometer (ASCAT) on board of the Meteorological Operational (METOP) satellite series (Figa-Saldana et al., 2002), will enhance the dynamic range of the sensitivity, since less spatial integration of the backscatter data takes place. This will improve the signal-to-noise ratio over pixels with low vegetation cover. In this case study, the temporal coverage of ERS-1 and ERS2 was very poor. ASCAT will take acquisitions every second day over Austria or more which will allow to obtain a much better sequence of wetting and drying of the soil surface and will provide more acquisitions during the short time period when the ground is snow free and not-frozen in mountain 
regions. This study also pointed to the importance of providing quality indicators with the scatterometer data which may assist users in selecting the most suitable data.

For improving the estimates of spatial and temporal soil moisture dynamics we are planning to reanalyse the scatterometer data. The revised methodology should account for azimuthal variations of the backscattering coefficient which is anticipated to improve the accuracy of the soil moisture estimates. For the soil moisture assimilation we are planning to test more powerful data assimilation techniques which can explicitly account for different sources of errors. These include the particle filtering approach (Moradkhani, 2005) and ensemble Kalman filter assimilation methodology (e.g. Reichle et al, 2002). For the regionalisation of model parameters and hydrological prediction in ungauged catchment we plan to mask data from regions which are affected by snow cover, data from forested regions and regions with large spatial soil moisture variability. We believe this will help derive more reliable regional links between catchment attributes and model parameter and exploit more effectively the value of scatterometer data in regions with sparse ground-based observations.

Acknowledgements. The authors would like to thank the Austrian Academy of Sciences, project HÖ 31, and the Austrian Science Fund, project L148-N10, for financial support. We would also like to thank the Austrian Hydrographic Service (HZB) for providing the hydrographic data.

Edited by: T. Wagener

\section{References}

Bárdossy, A. and Lehmann, W.: Spatial distribution of soil moisture in a small catchment. Part 1: geostatistical analysis, J. Hydrol., 206, 1-15, 1998.

Bergström, S.: Development and application of a conceptual runoff model for Scandinavian catchments, Dept. of Water Resour. Engineering, Lund Inst of Technol./Univ. of Lund, Bull. Ser. A, 52, 134 pp., 1976.

Blöschl, G. and Grayson R. B.: Advances in distributed hydrological modelling - towards a new paradigm, Proceedings of the Third International Conference on Water Resources and Environment Research (ICWRER) 22-26 of July 2002 in Dresden, Germany, Volume I. Dresden University of Technology, 17-25, 2002.

Blöschl, G.: Rainfall-runoff modelling of ungauged catchments, Article 133 in: Encyclopedia of Hydrological Sciences, edited by: Anderson, M. G., J. Wiley \& Sons, Chichester, pp. 20612080, 2005.

Boni, G., Entekhabi, D., and Castelli, F.: Land data assimilation with satellite measurements for the estimation of surface energy balance components and surface control on evaporation, Water Resour. Res., 37, 6, 1713-1722, 2001.

Ceballos, A., Scipal, K., Wagner, W., and Martinez-Fernandez, J.: Validation and downscaling of ERS Scatterometer derived soil moisture data over the central part of the Duero Basin, Spain, Hydrol. Processes, 19, 8, 1549-1566, 2005.

Daley, R.: Atmospheric Data Analysis, Cambridge University Press, Cambridge, UK, 1991.

Duan, Q., Sorooshian, S., and Gupta, V. K.: Effective and efficient global optimization for conceptual rainfall-runoff models, Water Res. R., 28, 1015-1031, 1992.

Entekhabi, D., Nakamura, H., and Njoku, E.G.: Solving the inverse problem for soil moisture and temperature profiles by sequential assimilation of multifrequency remotely sensed observations, IEEE Trans. Geosci. Remote Sens., 32, 2, 438-447, 1994.

Figa-Saldana, J., Wilson, J.J.W., Attema, E., Gelsthorpe, R., Drinkwater, M.R., and Stoffelen, A.: The advanced scatterometer (ASCAT) on the meteorological operational (METOP) platform: A follow on for European wind scatterometers, Can. J. Remote Sens., 28 , 404-412, 2002.

Francois, C., Quesney, A., and Ottlé, C.: Sequential Assimilation of ERS-1 SAR Data into a Coupled Land Surface-Hydrological Model Using an Extended Kalman Filter, J. Hydrometeorol., 4, 473-487, 2003.

Hoeben, R. and Troch, P. A.: Assimilation of active microwave observation data for soil moisture profile estimation, Water Resour. Res., 36, 10, 2805-2819, 2000.

Houser P., Goodrich.D., and Syed, K.: Runoff, precipitation, and soil moisture at Walnut Gulch, Chapter 6, in: Spatial Patterns in Catchment Hydrology: Observations and Modelling, edited by: Grayson, R. and Blöschl, G., Cambridge University Press, Cambridge, 125-157, 2000.

Jackson, T.: Estimation of surface soil moisture using microwave sensors, Article 54, in: Encyclopedia of Hydrological Sciences, edited by: Anderson, M. G., J. Wiley \& Sons, Chichester, pp. 799-810, 2005.

Leemans, R. and Cramer, W.: The IIASA database for mean monthly values of temperature, precipitation and cloudiness on a global terrestrial grid, Research Report RR-91-18, November 199, International Institute of Applied Systems Analyses, Laxenburg, 1991.

Lindström G.: A simple automatic calibration routine for the HBV model, Nordic Hydrology, 28, 3, 153-168, 1997.

Lindström, G., Johansson, B., Persson, M., Gardelin, M., and Bergström, S.: Development and test of the distributed HBV-96 hydrological model, J. Hydrol., 201, 272-288, 1997.

McLaughlin, D.: Recent advances in hydrologic data assimilation, U.S. National Report to the IUGG (1991-1994), Rev. Geophys., Supplement, 977-984, 1995.

Merz, R. and Blöschl, G.: Regionalisation of catchment model parameters, J. Hydrol., 287, 95-123, 2004.

Mészároš, I, Miklánek, P, and Parajka, J.: Solar energy income modelling in mountainous areas, ERB and NEFRIEND Proj. 5 Conf. Interdisciplinary Approaches in Small Catchment Hydrology: Monitoring and Research, edited by: Holko, L., Miklánek, P., Parajka, J., and Kostka, Z., Slovak NC IHP UNESCO/UH SAV, Bratislava, Slovakia, 127-135, 2002.

Milly, P. C. D.: Integrated remote sensing modeling of soil moisture: sampling frequency, response time, and accuracy of estimates, Integrated Design of Hydrological Networks, Proceedings of the Budapest Symposium, 201-211, IAHS Publication No. 158, 1986. 
Moradkhani, H., Hsu, K., Gupta, H. V., and Sooroshian, S.: Uncertainty assessment of hydrologic model states and parameters: sequential data assimilation using particle filter. Water Resour. Res., 41, W05012, doi:10.1029/2004WR003604, 2005.

Parajka, J., Merz, R., and Blöschl, G.: A comparison of regionalisation methods for catchment model parameters, Hydrol. Earth Syst. Sci., 9, 157-171, 2005a.

Parajka, J., Merz, R., and Blöschl, G.: Estimation of daily potential evapotranspiration for regional water balance modeling in Austria, 11th International Poster Day and Institute of Hydrology Open Day "Transport of Water, Chemicals and Energy in the Soil - Crop Canopy - Atmosphere System", Slovak Academy of Sciences, Bratislava, 299-306, 2003.

Parajka, J., Blöschl, G., and Merz, R.: Mapping of daily water balance components in Austria, XXIInd Conference of the Danubian Countries, September 2004, Brno, Czech Republic, 2004.

Parajka, J., Blöschl, G., and Merz, R: Comparison of two different soil moisture estimates at the regional scale: Scatterometer versus conceptual soil moisture accounting scheme, 13th International Poster Day and Institute of Hydrology Open Day "Transport of Water, Chemicals and Energy in the Soil - Crop Canopy Atmosphere System", Slovak Academy of Sciences, Bratislava, 411-422, 2005c.

Parajka, J., Merz, R., and Blöschl, G.: Regionale Wasserbilanzkomponenten für Österreich auf Tagesbasis, Österreichische Wasserund Abfallwirtschaft, 3-4, 43-56, 2005b.

Parajka, J., Merz, R., and Blöschl, G.: Uncertainty and multiple objective calibration in regional water balance modelling - Case study in 320 Austrian catchments, Hydrol. Processes, in press, 2006.

Pebesma, E. J.: Gstat user's manual, Dept. of Physical Geography, Utrecht University, Utrecht, The Netherlands, 2001.

Perrin, C., Michel, C., and Andréassian, V.: Does a large number of parameters enhance model performance? Comparative assessment of common catchment model structures on 429 catchments, J. Hydrol., 242, 275-301, 2001.

Reichle, R. H., McLaughlin, D.B., and Entekhabi, D.: Hydrologic data assimilation with ensemble Kalman filter, Mon. Wea. Rev., 130, 103-114, 2002.

Schrödter, H.: Verdunstung - Anwendungsorientierte Meßverfahren und Bestimmungsmethoden, Springer Verlag, Berlin, 1985

Schultz, G. and Engman, E.T.: Remote Sensing in Hydrology and Water Management, Springer, Berlin, 2000.

Schuurmans, J. M., Troch, P. A., Veldhuizen, A. A., Bastiaanssen, W. G. M., and Bierkens, M. F. P.: Assimilation of remotely sensed latent heat flux in a distributed hydrological model, Adv. Water Resour., 26, 151-159, 2003.
Scipal, K., Scheffler, C., and Wagner, W.: Soil moisture-runoff relation at the catchment scale as observed with coarse resolution microwave remote sensing, Hydrol. Earth Syst. Sci., 9(3), 173$183,2005$.

Scipal, K., Wagner, W., Trommler, M., and Naumann, K.: The global soil moisture archive 1992-2000 from ERS scatterometer data: First results, Igarss 2002: Ieee International Geoscience and Remote Sensing Symposium and 24th Canadian Symposium on Remote Sensing, Vols I-Vi, Proceedings - Remote Sensing: Integrating Our View of the Planet, 1399-1401, 2002.

Seibert, J.: Regionalisation of parameters for a conceptual rainfallrunoff model, Agr. For. Met., 98-99, 279-293, 1999.

Ulaby, F. T., Moore, R. K., and Fung, A. K.: Microwave remote sensing: Active and passive, Volume 2, Artech House, Noorwood, 609 pp., 1982.

Wagner, W., Lemoine, G., and Rott, H.: A method for estimating soil moisture from ERS scatterometer and soil data, Remote Sensing of Environment, 70, 2, 191-207, 1999b.

Wagner, W., Lemoine, G., Borgeaud, M., and Rott, H.: A study of vegetation cover effects on ERS scatterometer data, Ieee Transactions on Geoscience and Remote Sensing, 37(2), 938-948, 1999a.

Wagner, W., Noll, J., Borgeaud, M., and Rott, H.: Monitoring soil moisture over the Canadian Prairies with the ERS scatterometer, Ieee Transactions on Geoscience and Remote Sensing, 37, 1, 206-216, 1999c.

Walker, J. P., Willgoose, G. R., and Kalma, J. D.: One-dimensional soil moisture profile retrieval by assimilation of near-surface observations: A comparison of retrieval algorithms, Adv. Water Resour., 24, 6, 631-650, 2001.

Western, A. W. and Blöschl, G.: On the spatial scaling of soil moisture, J. Hydrol., 217, 203-224, 1999.

Western, A. W., Blöschl, G., and Grayson, R. B. Geostatistical characterisation of soil moisture patterns in the Tarrawarra catchment, J. Hydrol., 205, 20-37, 1998.

Western, A., Grayson, R., and Blöschl, G.: Scaling of soil moisture: a hydrologic perspective, Ann. Rev. Earth and Planetary Sci., 30 , 149-180, 2002.

Wigneron, J. P., Olioso, A., Calvet, J. C., and Bertuzzi, P.: Estimating root zone soil moisture from surface soil moisture data and soil-vegetation-atmosphere transfer modelling, Water Res. R., 35, 12, 3735-3745, 1999.

Wismann V. and Woodhouse, I.: Monitoring of seasonal thawing in Siberia with ERS scatterometer data, IEEE Trans. Geoscience and Remote Sensing, 38, 4, 1804-1809, 2000. 